\title{
The Swiss Priority Programme in Informatics Research, Module Parallelism: Guest Editor's Introduction
}

\author{
HELMAR BURKHART \\ Institut für Informatik, Universität Basel, Mittlere Strasse 142, CH-4056 Basel, Switzerland; e-mail: burkhart@ifi.unibas.ch
}

Switzerland has one of the highest density of computer systems in the world because banks, insurance companies, and other branches of industry strongly depend on a high degree of expertise in Informatics. Although certain research groups at the Swiss federal institutes and universities have established an international reputation in Informatics, there are still many problems. For example, there are currently no major Swiss software houses and as a result industry is outsourcing more and more work to transnational companies. Only few new Swiss projects have been started recently which of course causes problems for young engineers. Having strong research teams at the universities is not enough; transfer of the know-how to advanced application fields is necessary. Mixed teams of engineers from universities and industry need to guarantee a proper return on investment. Precompetitive research with programs explicitly asking for exploitation plans are becoming more and more dominant.

Is this a Swiss specialty? Not at all. All major international research programs in the 1990s had or have this goal. In 1992, the Swiss National Science Foundation started an initiative in this direction, called the Priority Programme in Informatics Research SPP IF. Three topics were chosen as priority fields: safe complex systems, knowledge-based systems, and massively parallel systems. In this issue we report on five projects of the parallelism module.

The projects demonstrate the variety that parallelism offers today:
- New architectures and systems always attracted people. Study the MUSIC approach, a system based on digital signal processors, that has been used in application fields such as neural network simulation and molecular dynamics.

- Or have a look at the Mantra Project, which describes interdisciplinary research in artificial neural network design, implementation, and application.

- Or enjoy the results of the Gigaview project, which targets towards parallelism support for advanced multimedia applications.

- Of course software is a challenge; it may be THE challenge. The Basel group has new ideas that emphasize the software engineering vocabulary.

- Parallelism is usually applied in interdisciplinary teams. This aspect is nicely demonstrated in the SPINET project where different groups work together.

From a scientific point of view, all these projects have been successful. The transfer of results to industry, however, needs time. Some of the projects can already report success while others need more time. Don't hesitate to contact these groups if you think they can help in your business!

. . . and if you would like to have information about other parts of the program, contact the Swiss National Science Foundation, Wildhainweg 20, CH-3001 Bern, Switzerland. 

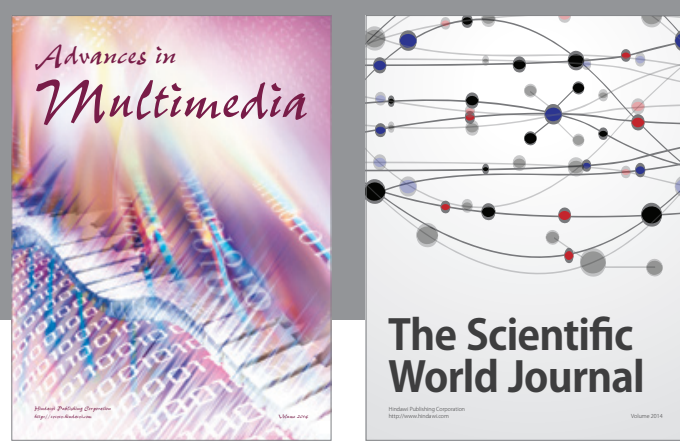

The Scientific World Journal
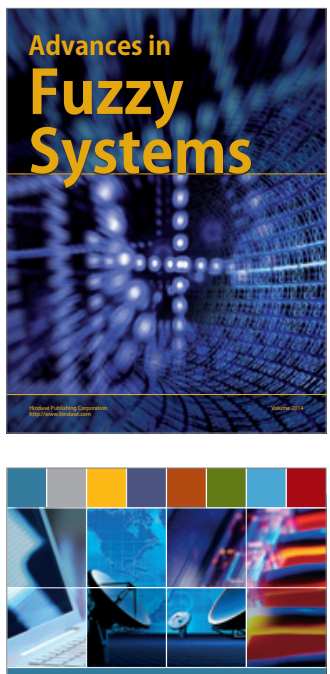

Computer Networks and Communications
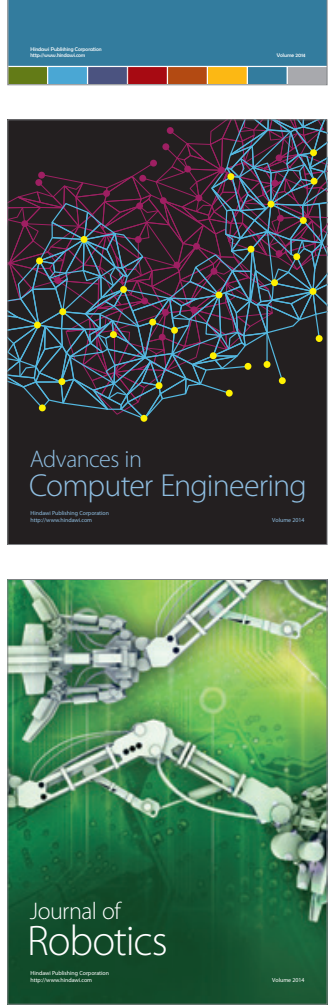
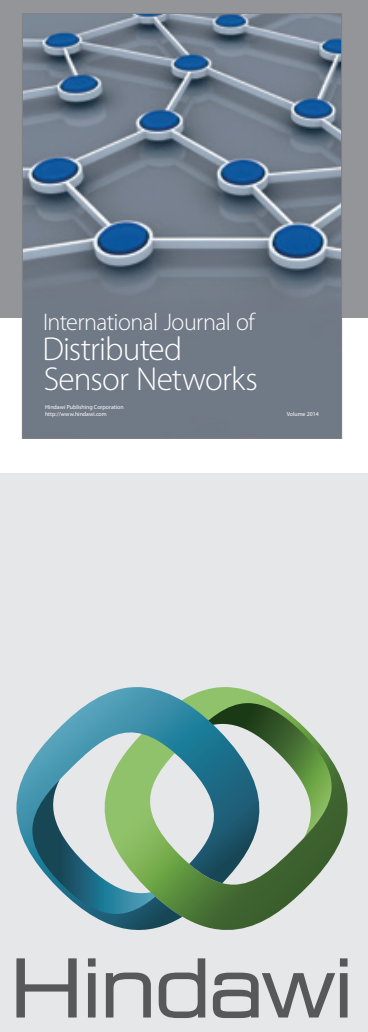

Submit your manuscripts at

http://www.hindawi.com
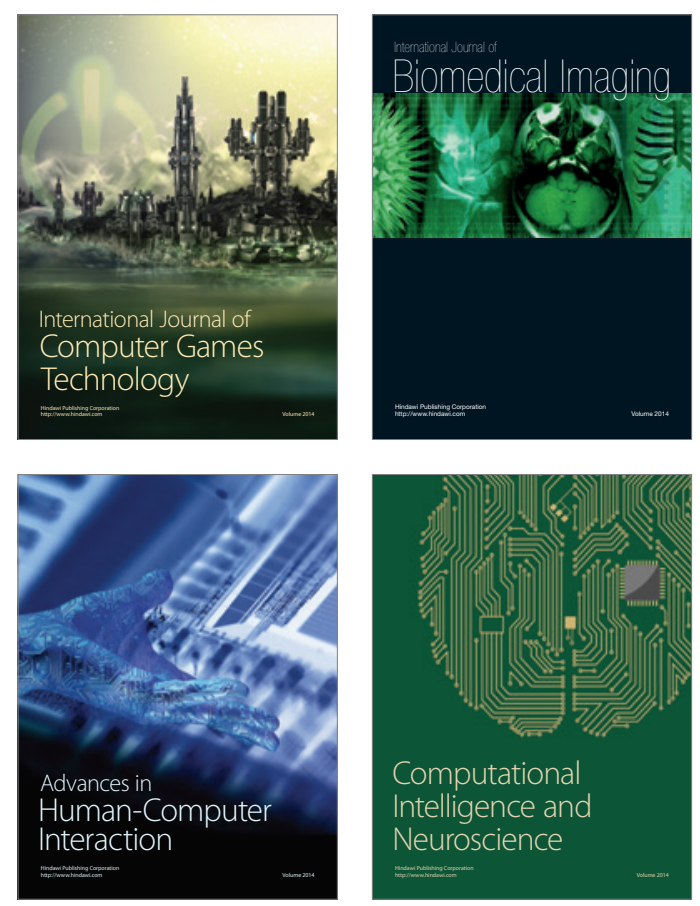
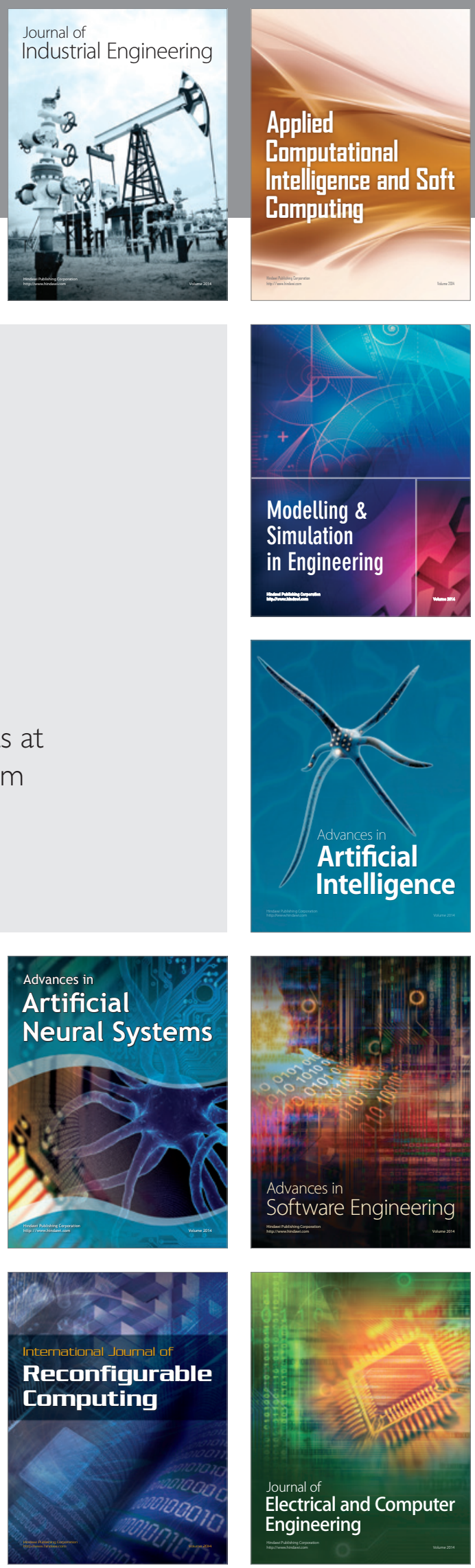